\title{
Immune Hemolytic Disease of the Newborn
}

\author{
${ }^{1}$ Richa Saxena, ${ }^{2}$ Priyanka Diwan
}

\begin{abstract}
Hemolytic anemia caused by blood group incompatibility is an important cause of neonatal morbidity and mortality. Hemolytic disease of the fetus and newborn (HDFN), which is also termed as alloimmune HDFN or erythroblastosis fetalis, occurs due to destruction of red blood cells (RBCs) of the fetus or neonate by maternal immunoglobulin $\mathrm{G}$ antibodies. Under the conditions of anemia, the fetal bone marrow initiates production of immature erythroblasts into the fetal peripheral circulation, resulting in various manifestations of erythroblastosis fetalis, including conditions, such as hydrops fetalis, icterus gravis neonatorum, and congenital anemia of the newborn. Different approaches are being employed for the treatment of fetal anemia, such as intrauterine blood transfusion and exchange transfusion that takes place after birth. Recently, use of intravenous immunoglobulin (IVIg) has also been considered for the management of jaundice in newborns associated with hemolytic diseases.

Keywords: Exchange transfusion, Hemolytic disease of newborn, Intrauterine blood transfusion, Intravenous immunoglobulin, Jaundice in newborn, Rh isoimmunization.
\end{abstract}

How to cite this article: Saxena R, Diwan P. Immune HemoIytic Disease of the Newborn. World J Anemia 2018;2(1):21-25.

\section{Source of support: Nil}

Conflict of interest: None

\section{INTRODUCTION}

Hemolytic anemia in the fetus or the neonate is commonly caused by either by ABO or Rh blood group incompatibility. Erythroblastosis fetalis, also known as hemolytic disease of the newborn (HDN), is an umbrella term used to denote various hemolytic disorders resulting due to blood group incompatibility. ${ }^{1}$ Clinical manifestations of erythroblastosis fetalis include hydrops fetalis, icterus gravis neonatorum, and congenital anemia of the newborn.

\section{ETIOLOGY}

Hemolytic disease of the newborn is a syndrome resulting from hemolytic destruction of circulating fetal red cells in uterus, and after delivery. It is caused by transplacental

\footnotetext{
${ }^{1}$ Head, ${ }^{2}$ Medical Development Editor

1,2 Jaypee Brothers Medical Publishers, New Delhi, India

Corresponding Author: Richa Saxena, Head, Jaypee Brothers Medical Publishers, New Delhi, India, e-mail: synapse94@ hotmail.com
}

Flow Chart 1: Pathogenesis of fetal erythroblastosis fetalis

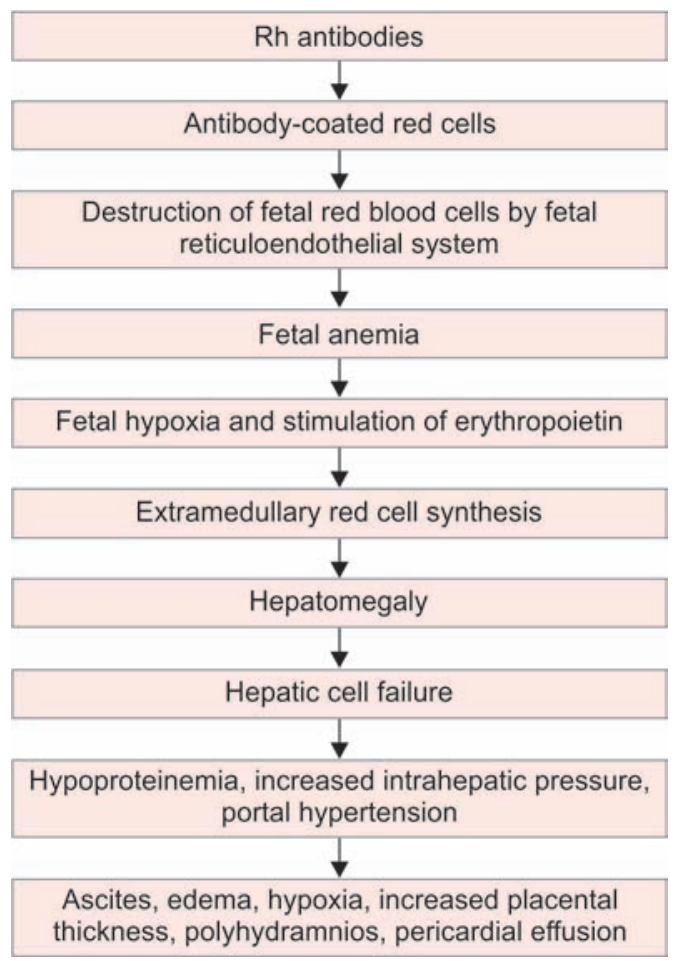

transmission of maternal antibodies, usually resulting from maternal and fetal Rh blood group incompatibility (Flow Chart 1 ). ${ }^{2}$ Hemolysis produced due to Rh incompatibility may produce profound anemia, which may even result in fetal death in utero. ${ }^{3}$ As a compensatory mechanism to anemia, the fetal bone marrow starts producing immature erythroblasts into the fetal peripheral circulation, causing erythroblastosis fetalis. The overproduction of erythroblasts can produce enlargement of liver and spleen, resulting in development of hepatomegaly and splenomegaly respectively. ABO incompatibility is also rarely associated with HDN.

\section{CLINICAL MANIFESTATIONS}

\section{Congenital Anemia}

Excessive destruction of RBCs results in excessive production of bilirubin, which is responsible for producing hyperbilirubinemia and jaundice. Low levels of jaundice are unlikely to cause any harm. However, if left untreated, uncontrollable hyperbilirubinemia leads to deposition of bilirubin in the brain, resulting in permanent damage and development of kernicterus, which can cause neurodevelopmental problems, deafness, speech 
problems, cerebral palsy, mental retardation, or motor and speech delay. ${ }^{4}$ Postnatal jaundice can be treated with phototherapy and exchange transfusion.

\section{Hydrops Fetalis}

This is a condition characterized by an accumulation of fluids within the baby's body, resulting in development of ascites, pleural effusion, pericardial effusion, skin edema, etc. In many cases, it may also cause polyhydramnios and placental edema (Fig. 1). Pleural effusion may interfere with the normal process of breathing, whereas pericardial effusion may be associated with congestive heart failure. ${ }^{5}$ The fetus is particularly susceptible to interstitial fluid accumulation due to increased capillary permeability, hypoproteinemia, and obstruction to lymphatic return.

\section{DIFFERENTIAL DIAGNOSIS}

Differential diagnosis of hemolytic anemia in a newborn infant includes the following:

- Isoimmunization ${ }^{6}$

- RBC enzyme disorders, e.g., glucose-6-phosphate dehydrogenase and pyruvate kinase deficiency

- Disorders of hemoglobin synthesis, e.g., alphathalassemias

- $\quad$ RBC membrane abnormalities, e.g., hereditary spherocytosis, elliptocytosis, etc.

- Hemangiomas (Kasabach-Merritt syndrome)

- Acquired conditions, such as sepsis, infections with TORCH (toxoplasmosis, other agents, rubella [also known as German measles], cytomegalovirus, and herpes simplex) or parvovirus B19, etc.

\section{TREATMENT OF FETAL ANEMIA}

Treatment of the baby born with hemolytic anemia comprises of the following options:

- In utero transfusion, if fetal anemia is severe.

- Exchange transfusion after birth.

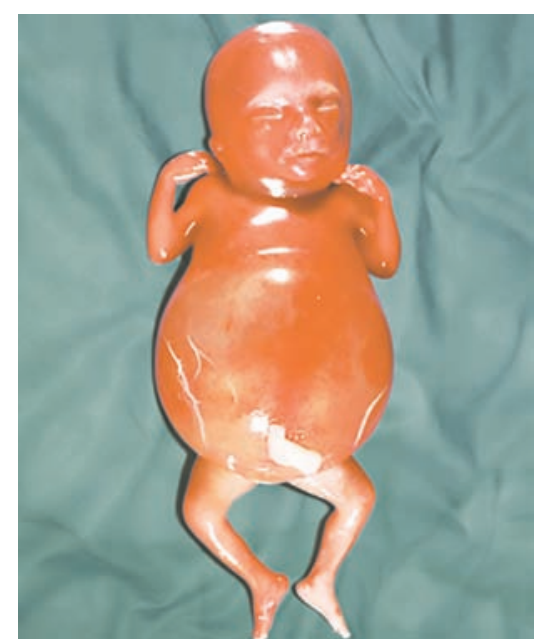

Fig. 1: Hydrops fetalis associated with fetal ascites and skin edema

\section{Fetal Intrauterine Blood Transfusion}

There are two techniques that are used to deliver intrauterine blood transfusion to a baby before birth. ${ }^{7}$ These include intraperitoneal transfusion and intravascular transfusion. One or more transfusions may be necessary to treat the episode of anemia, hyperbilirubinemia, and bleeding. The amount of blood to be transfused (in milliliters) is calculated by multiplying number of weeks of gestation over 20 with 10 . For example at 34 weeks of gestation the amount of blood required to be transfused would be equal to $(34-20) \times 10=140 \mathrm{~mL}$. The transfusion process can be repeated at weekly or 2 -weekly intervals. Following the process of transfusion, fetal surveillance in the form of biweekly cardiotocography and weekly ultrasound examinations in order to ensure fetal well-being must be performed.

\section{Intraperitoneal Transfusion}

With this method, a needle is inserted through the mother's abdomen and uterus into the baby's peritoneal cavity under ultrasound guidance. The RBCs injected into the baby's abdominal cavity are absorbed by the subdiaphragmatic lymphatics into the bloodstream. Rh-negative packed red cells of the blood group type $\mathrm{O}$ having the hematocrit of $80 \%$ that have been cross-matched with the mother are usually transfused. ${ }^{8}$

\section{Intravascular Blood Transfusion}

In this method, Rh-negative packed red cells of the blood group type $\mathrm{O}$ having the hematocrit of $80 \%$ that have been cross-matched with the mother are usually transfused through the fetal umbilical vein. It is the most preferred method for therapy, as it is speedily effective in the treatment of fetal anemia and reversal of hydrops. ${ }^{9}$

\section{Exchange Transfusion}

Exchange transfusion (Fig. 2) is a potentially life-saving procedure that is done to counteract the effects of serious

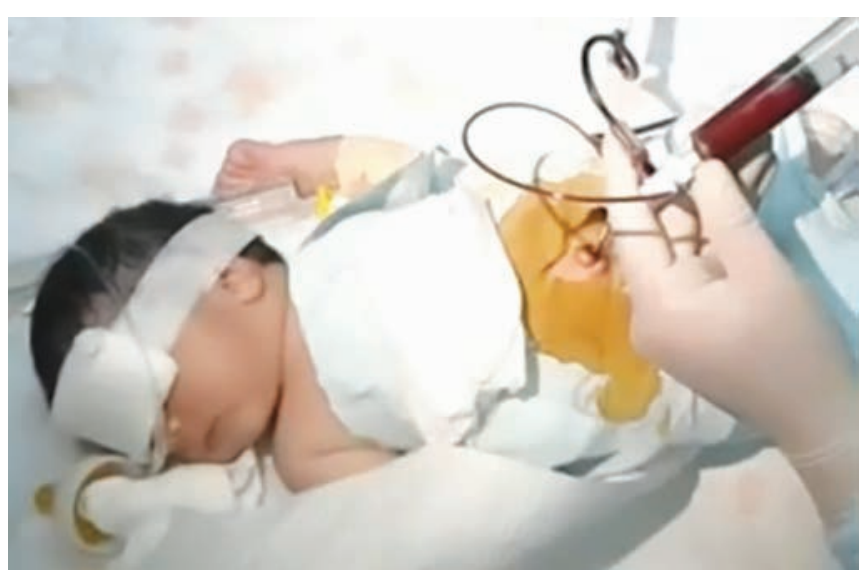

Fig. 2: Exchange transfusion 
jaundice related to hemolytic anemia in a newborn child born to the mother with Rh incompatibility. ${ }^{10}$ This procedure helps in correcting neonatal anemia and congestive heart failure. ${ }^{11}$ It also helps in removing the circulatory antibodies. The procedure of exchange transfusion involves slow removal of the baby's blood and its replacement with fresh donor blood or plasma (Fig. 3). The value of cord bilirubin level higher than $4.5 \mathrm{mg} / \mathrm{dL}$ or cord hemoglobin lower than $11 \mathrm{~g} / \mathrm{dL}$ indicates usage of exchange transfusion. ${ }^{12}$

Steps to be taken prior to the birth:

- Arranging blood: If a severely affected infant with $\mathrm{Rh}$ hemolytic disease is anticipated at birth, it may be necessary to arrange ABO compatible (with the baby), Rh-negative whole blood with the specific volume. If ABO compatible blood is not available, O negative blood can be used. The blood should be cross-matched with the infant's serum. The total volume of exchange should not exceed one adult unit of blood (450-500 mL). The volume of blood to be exchanged is calculated using the following formula:

Blood volume $(\mathrm{mL}) \times$

Volume exchanged $(\mathrm{mL})=\frac{(\mathrm{Hb} \text { desired }-\mathrm{Hb} \text { initial })}{(\mathrm{Hb} \text { donor }-\mathrm{Hb} \text { initial })}$

where blood volume $=70$ to $90 \mathrm{~mL} / \mathrm{kg}$ for term and 85 to $110 \mathrm{~mL} / \mathrm{kg}$ for preterm infants.

- Surfactant: This may be required in cases of preterm infants.

- Catheters (e.g., Angiocath): These may be required for immediate drainage of hydropic fluid.
Steps to be taken at the time of birth:

- Resuscitation: At birth, the major problems are cardiopulmonary and relate to effects of severe anemia, hydrops, and prematurity. Hydropic infants must be intubated immediately and assisted ventilation must be commenced with oxygen.

- Obtaining cord blood for performing various tests: These would include bilirubin (total and direct), albumin, blood type and $\mathrm{Rh}$, direct Coombs test, complete blood count, platelets, reticulocyte count, and nucleated RBCs.

- Correction of metabolic acidosis: This can be done by administration of an alkali. ${ }^{13}$

- Correction of anemia: If arterial blood pressure is low, administration of a simple transfusion of packed RBCs may prove to be useful. ${ }^{14}$

- Monitoring of blood glucose levels: Blood sugar levels must be frequently monitored and hypoglycemia if detected must be immediately corrected.

- Monitoring of platelet levels: Platelet transfusion must be considered for platelet counts less than $20 \mathrm{mg} / \mathrm{dL}$ in a term infant with HDN.

- Monitoring of bilirubin levels: The process is carried out in high-risk infants or severely affected fetuses if there is an increase in serum bilirubin levels at rate that exceeds 0.4 to $0.6 \mathrm{mg} / \mathrm{dL}{ }^{15}$ The serum bilirubin concentration may rise by 2 hours after completion of the exchange transfusion. Therefore, the serum bilirubin concentration should be monitored at 2 to 4 hours intervals after exchange. In case the serum bilirubin levels continue to remain elevated, phototherapy (Fig. 4) may be used.

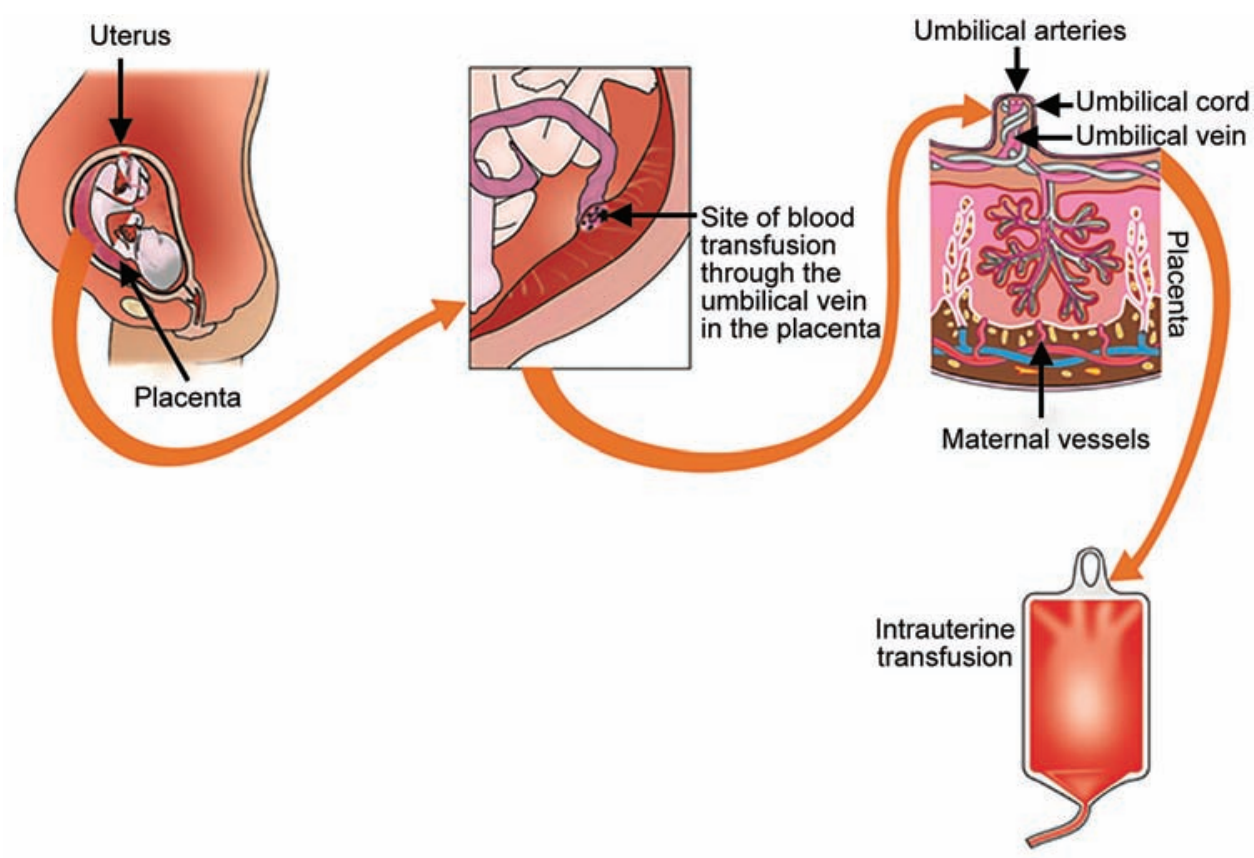

Fig. 3: Process of exchange transfusion 


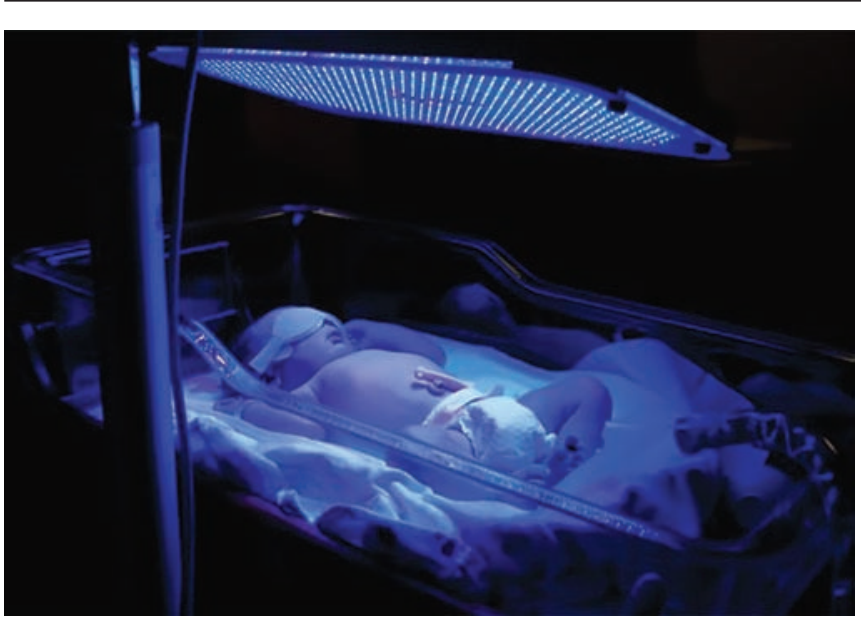

Fig. 4: Role of intensive phototherapy

- The infant may be fed after 2 to 4 hours following the procedure of exchange transfusion and initiated on folic acid at dose of 100 to $200 \mu \mathrm{g} /$ day. Folate reserves are lower in newborn and neonatal blood is replaced with adult blood through exchange transfusion. ${ }^{16}$

Risks: The possible complications of the procedure include the following ${ }^{17}$ :

- Formation of blood clots and risk of thrombosis

- Alteration in the blood chemistry resulting in abnormalities like hyperkalemia, hypokalemia, hypocalcemia, hypoglycemia, and metabolic acidosis

- Heart and lung problems

- Infection

- Shock due to inadequate replacement of blood

- Neonatal mortality

\section{INTRAVENOUS IMMUNOGLOBULINS FOR MANAGEMENT OF HDN}

Hemolytic anemia resulting due to blood group incompatibility (both $\mathrm{Rh}$ and $\mathrm{ABO}$ ) is an important cause for jaundice in a neonate. Traditionally, two main therapeutic modalities have been used for treating jaundice in the neonate and for avoiding neurological complications which may develop in association with kernicterus. These therapeutic modalities include phototherapy and exchange transfusion. Exchange transfusion is an invasive procedure which may be associated with its own complications. Recently, use of IVIgs has been suggested as an alternative therapy for treatment of cases with jaundice resulting from isoimmune hemolytic jaundice (Fig. 5).

It has been often proposed that the prophylactic use of IVIg helps in reducing the requirement for exchange transfusions in neonates with rhesus hemolytic disease. In a randomized, double-blind, placebo-controlled trial by Smits-Wintjens et al, ${ }^{18}$ neonates with rhesus hemolytic disease were assigned IVIg in the dosage of $0.75 \mathrm{gm} / \mathrm{kg}$ body weight. The results of this study showed that the

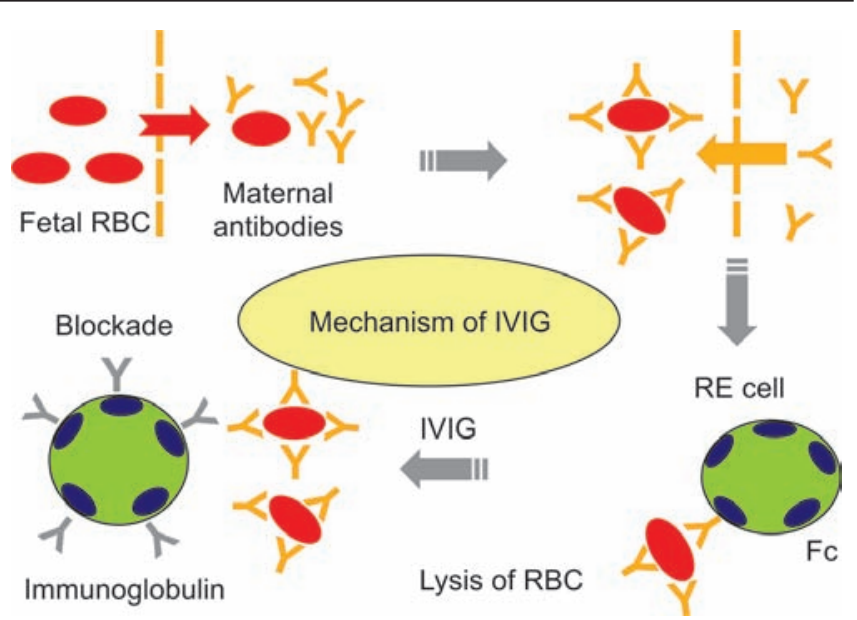

Fig. 5: Mechanism of action of intravenous immunoglobulin. (RE: reticuloendothelial)

prophylactic use of IVIg does not reduce the requirement for exchange transfusion in the neonates with hemolytic disease. Moreover, it also does not reduce the rates of other adverse neonatal outcomes. On the contrary, a Cochrane review by Alcock and Liley ${ }^{19}$ has shown that use of this therapy may result in a significant reduction in the requirement for exchange transfusion. However, this Cochrane review was associated with several limitations. Only three low-quality studies were included in this review.

A controlled study by Alpay et $\mathrm{al}^{20}$ has shown that high-dose IVIg therapy in newborns with $\mathrm{ABO}$ or $\mathrm{Rh}$ hemolytic diseases helps in controlling hemolysis, serum bilirubin levels, and the requirement for blood exchange transfusion. In infants with $\mathrm{ABO}$ hemolytic disease, use of IVIgs has neither helped in reducing the requirement for phototherapy nor helped in reducing the duration of hospitalization. ${ }^{21}$ There is a requirement of further welldesigned studies in future before IVIg therapy can be routinely used for the treatment of isoimmune hemolytic jaundice due to Rh or ABO incompatibility. Dosage and administration schedule of IVIgs also need to be decided with the help of well-designed randomized clinical trials.

\section{CONCLUSION}

$\mathrm{Rh}$ isoimmunization is the most significant cause for hemolytic anemia in the newborn babies. Jaundice and kernicterus are important complications of the hemolytic anemia in neonates. Phototherapy and exchange transfusion presently remain the modalities of choice for management of jaundice in babies with neonatal hemolytic anemia. Recently, IVIgs are being used for the treatment of jaundice in newborn infants with hemolytic anemia. However, the available evidence has presented with conflicting results regarding the efficacy of this therapy. Further well-designed studies would be required in future before IVIg therapy can be recommended for routine use in cases of isoimmune hemolytic jaundice. 


\section{REFERENCES}

1. Murray NA, Roberts IA. Haemolytic disease of the newborn. Arch Dis Child Fetal Neonatal Ed 2007 Mar;92(2):F83-F88.

2. Fanaroff, AA.; Martin, RJ.; editors. Behrman's neonatalperinatal medicine: diseases of the fetus and infant. 3rd ed. St Louis (MO): Mosby; 1983.

3. Bowman J. Rh-immunoglobulin: Rh prophylaxis. Best Pract Res Clin Haematol 2006;19(1):27-34.

4. Shapiro SM. Definition of the clinical spectrum of kernicterus and bilirubin-induced neurologic dysfunction (BIND). J Perinatol 2005 Jan;25(1):54-59.

5. Derderian SC, Jeanty C, Fleck SR, Cheng LS, Peyvandi S, Moon-Grady AJ, Farrell J, Hirose S, Gonzalez J, Keller RL, et al. The many faces of hydrops. J Pediatr Surg 2015 Jan;50(1): 50-54, discussion 54.

6. de Haas M, Thurik FF, Koelewijn JM, van der Schoot CE. Haemolytic disease of the fetus and newborn. Vox Sang 2015 Aug;109(2):99-113.

7. Lindenburg IT, van Kamp IL, Oepkes D. Intrauterine blood transfusion: current indications and associated risks. Fetal Diagn Ther 2014 Jun;36(4):263-271.

8. Howe DT, Michailidis GD. Intraperitoneal transfusion in severe, early-onset Rh isoimmunization. Obstet Gynecol 2007 Oct;110(4):880-884.

9. Grannum PA, Copel JA, Moya FR, Scioscia AL, Robert JA, Winn HN, Coster BC, Burdine CB, Hobbins JC. The reversal of hydrops fetalis by intravascular intrauterine transfusions in severe isoimmune fetal anemia. Am J Obstet Gynecol 1988 Apr;158(4):914-919.

10. MedlinePlus. Exchange transfusion. Bethesda (MD): U.S. National Library of Medicine; 2017. [cited 2018 Jul]. Available from: https:/ / medlineplus.gov/ency/article/002923.htm.

11. Wiener AS, Wexler IB, Grundfast TH. Therapy of erythroblastosis fetalis with exchange transfusion. Bull N Y Acad Med 1947 Apr;23(4):207-220.
12. Zipursky, A.; Bowman, JM. Isoimmune hemolytic diseases. In: Nathan DG, Oski FA, editors. Hematology of infancy and childhood. 4th ed. Philadelphia (PA): WB Saunders; 1993. pp. 44-73.

13. Levraut J, Grimaud D. Treatment of metabolic acidosis. Curr Opin Crit Care 2003 Aug;9(4):260-265.

14. Liumbruno G, Bennardello F, Lattanzio A, Piccoli P, Rossetti G. Recommendations for the transfusion of red blood cells. Blood Transfus 2009 Jan;7(1):49-64.

15. Wennberg RP, Depp R, Heinrichs WL. Indications for early exchange transfusion in patients with erythroblastosis fetalis. J Pediatr 1978 May;92(5):789-792.

16. Purugganan, G.; Leikin, S.; Gautier, G. Isoimmune hemolytic diseases. In: Nathan DG, Oski FA, editors. Hematology of infancy and childhood. Philadelphia (PA): Elsevier Health Sciences; 2009. p. 87-99.

17. Patra K, Storfer-Isser A, Siner B, Moore J, Hack M. Adverse effects associated with neonatal exchange transfusion in the 1990s. J Pediatr 2004 May;144(5):626-631.

18. Smits-Wintjens VE, Walther FJ, Rath ME, Lindenburg IT, te Pas $\mathrm{AB}$, Kramer CM, Oepkes D, Brand A, Lopriore E. Intravenous immunoglobulin in neonates with rhesus hemolytic disease: a randomized controlled trial. Pediatrics 2011 Apr;127(4): 680-686.

19. Alcock GS, Liley H. Immunoglobulin Infusion for isoimmune hemolytic jaundice in neonates. Cochrane Database Syst Rev 2002 Jul;3:CD003313.

20. Alpay F, Sarici SU, Okutan V, Erdem G, Ozcan O, Gökçay E. High-dose intravenous immunoglobulin therapy in neonatal immune haemolytic jaundice. Acta Paediatr 1999 Feb;88(2): 216-219.

21. Miqdad AM, Abdelbasit OB, Shaheed MM, Seidahmed MZ, Abomelha AM, Arcala OP. Intravenous immunoglobulin G (IVIG) therapy for significant hyperbilirubinemia in ABO hemolytic disease of newborn. J Matern Fetal Neonatal Med 2004 Sep;16(3):163-166. 